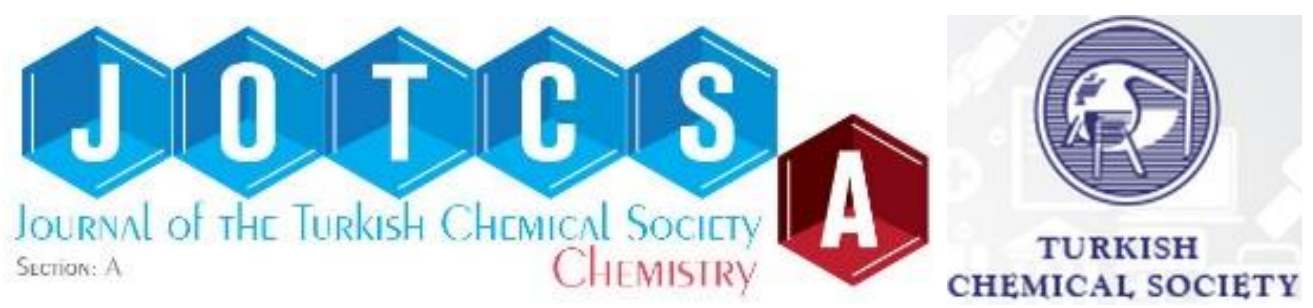

\title{
Synthesis of Chlorotoxin by Native Chemical Ligation
}

\author{
Ulvi KARACA D1, M. Seçkin KESİCi \\ ${ }^{1}$ Middle East Technical University, 06800, Ankara, Turkey \\ *Corresponding author. Salih ÖZÇUBUKÇU. osalih@metu.edu.tr
}

\begin{abstract}
Chlorotoxin (CLTX) is a neurotoxin found in the venom of the Israeli scorpion, Leirius quinquestriatus. It contains 36-amino acids with four disulfide bonds and inhibits lowconductance chloride channels. CLTX also binds to matrix metalloproteinase-2 (MMP-2) selectively. The synthesis of chlorotoxin using solid phase peptide synthesis (SPPS) is very difficult and has a very low yield $(<1 \%)$ due to high number of amino acid sequence. In this work, to improve the efficiency of the synthesis, native chemical ligation was applied. In this strategy, chlorotoxin sequence was split into two parts having 15 and 21 amino acids. 21-mer peptide was synthesized in its native form based on 9-fluorenylmethyloxycarbonyl (Fmoc) chemistry. 15-mer peptide was synthesized having o-aminoanilide linker on C-terminal. These parts were coupled by native chemical ligation to produce chlorotoxin.
\end{abstract}

Keywords: Chlorotoxin, solid phase peptide synthesis, native chemical ligation.

Submitted: March 21, 2018. Accepted: April 17, 2018.

Cite this: Karaca U, Kesici M, Özçubukçu S. Synthesis of Chlorotoxin by Native Chemical Ligation. JOTCSA. 2018;5(2):719-26.

DOI: http://dx.doi.org/10.18596/jotcsa.408517.

*Corresponding author. E-mail: osalih@metu.edu.tr . 


\section{INTRODUCTION}

Chlorotoxin (CLTX) is a venom peptide that was first isolated from the Israeli scorpion, Leirius quinquestriatus. It is a neurotoxic peptide having 36 -amino acids and four disulfide bonds. It inhibits low-conductance chloride channels (1). It has also been shown that CLTX is an inhibitor of matrix metalloproteinase-2 (MMP-2) which is a protease that functions in the breakdowns of the extracellular matrix (2). The CLTX is classified as an inhibitor cysteine knot (knottin) due to its "disulfide through disulfide knot" structure. Fluorescent dye conjugated CLTX derivatives were used in the imaging of cancer tissues (3). Iodine radioconjugated CLTX with a trial name TM601 , was in phase II clinical trial for its selective binding to glioma cells without affecting healthy cells $(4,5)$. Boc-SPPS was used in the chemical synthesis of chlorotoxin and its derivatives $(6)$. There are also examples of one-step Fmoc-based SPPS synthesis of chlorotoxin, however the yields after purification and folding were lower than 1\% (7). In general, Fmoc-based SPPS suffers from the low efficiency of coupling reactions after certain length of peptide sequence has been reached due to aggregation of peptide under basic reaction conditions. This results in formation of deletion products and causes difficulties in the purification of peptides (8).

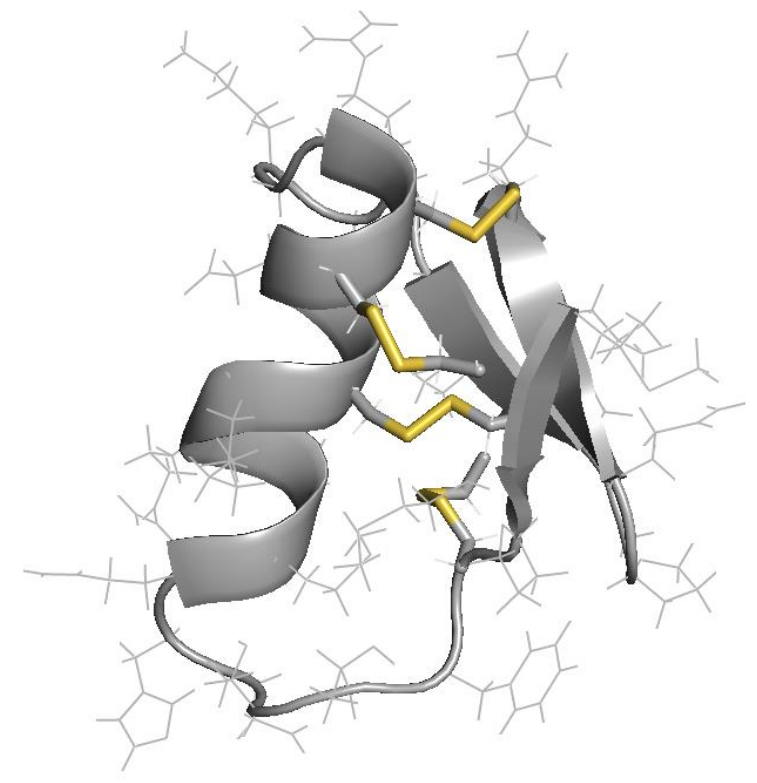

Figure 1. 3D structure of CLTX. Disulfide bridges are shown in yellow (Obtained from Protein Data Bank: $1 \mathrm{CHL})$.

Kent and Dawson developed (8) native chemical ligation ( $N C L$ ), which is the method commonly used in the synthesis of long peptides from the reaction of two native peptides which are synthesized and purified separately. One peptide has a thioester at its C-terminal and the other peptide has a cysteine at the $N$-terminal of the peptide sequence. Under certain reaction conditions, thiol sidechain in cysteine reacts with thioester moiety selectively and afterwards Sto- $\mathrm{N}$ acyl shift that forms an amide bond to form native peptide as ligation product. 
NCL method is developed based on Boc-SPPS. The synthesis of thioester moiety at the C-terminal of the peptide is not suitable for Fmoc-based SPPS. But recently, Dawson et al. developed a new native chemical ligation method which is suitable for Fmoc-SPPS (10). In this method, oaminoanilides are used as linkers in the synthesis of the peptide and this linker further converted into $\mathrm{N}$-acyl urea group at the end of the peptide sequence before cleaving from the resin. The cleaved product is stable under the acidic conditions. However, in neutral conditions, this acyl urea peptide product can undergo rapid thiolysis, and forms thioester peptide to be used in the native chemical ligation.

In this work, chlorotoxin is synthesized by native chemical ligation based on Fmoc-SPPS strategy developed by Dawson et al. $(9,10)$.

\section{MATERIALS AND METHODS}

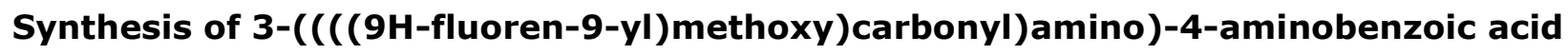<smiles>Nc1ccc(C(=O)O)cc1N</smiles><smiles>CC(C)OOC(=O)C#N</smiles><smiles>Nc1ccc(C(=O)O)cc1NOCF</smiles>

Based on the literature procedure (8), to a solution of 3,4-diaminobenzoic acid $(1.0 \mathrm{~g}, 6.6 \mathrm{mmol})$ in $\mathrm{NaHCO}_{3}$ (84 mg) water/acetonitrile $(1: 1,20 \mathrm{~mL}$ ) was added $N$-(9-fluorenylmethoxy carbonyloxy) succinimide (Fmoc-OSu) $(2.2 \mathrm{~g}, 6.6 \mathrm{mmol})$ in small quantities. After stirring overnight at room temperature, acidification with $1 \mathrm{M} \mathrm{HCl}(\mathrm{aq})$ formed a precipitate that was filtered, washed with methanol, cold ether and $\mathrm{n}$-hexane. The solid was dried under vacuum affording the desired compound as a pale white solid $(1.7 \mathrm{~g}, 70 \%) .{ }^{1} \mathrm{H} \mathrm{NMR}$ (400 MHz, $\mathrm{d}_{6}-\mathrm{DMSO}$ ) $\delta: ~ 4.29-4.40(\mathrm{~m}, 3 \mathrm{H}), 6.72(\mathrm{~d}, J=8.3 \mathrm{~Hz}, 1 \mathrm{H}), 7.33-7.36(\mathrm{~m}, 2 \mathrm{H}), 7.44(\mathrm{t}, J=7.4 \mathrm{~Hz}, 2 \mathrm{H}), 7.51$ $(\mathrm{d}, J=7.8 \mathrm{~Hz} 1 \mathrm{H}), 7.72-7.80(\mathrm{~m}, 3 \mathrm{H}), 7.91(\mathrm{~d}, J=7.4 \mathrm{~Hz}), 8.78(\mathrm{~s}, 1 \mathrm{H})$.

\section{General procedure for solid phase peptide synthesis $(8,10)$}

Loading the amino acid and coupling with an Fmoc-protected amino acid: $169 \mathrm{mg}(0.1 \mathrm{mmol})$ Rink amide resin was weighed in a reaction vessel. It was washed with DMF (2x) and swollen in 5-6 mL of DMF for 40-45 min. After Fmoc-deprotection of resin, Fmoc-protected amino acid ( 0.45 mmol, 4.5 eq.) (Fmoc-protected 3,4-diaminobenzoic acid acts like Fmoc-protected amino acid) dissolved in HBTU $(0.8 \mathrm{~mL}, 0.5 \mathrm{M}$ in DMF) then DIEA $(140 \mu \mathrm{L})$ was added. After addition of DIEA, the solution was mixed and added to the resin in 30 seconds at max. The mixture was allowed to stand for 15 minutes and agitated in every $5 \mathrm{~min}$. Then, the solution was filtered and the resin was washed with DMF. This process repeated one more time. The reaction was monitored by Kaiser test. 
Fmoc Deprotection: The Fmoc group was removed by treating the pre-swollen resin with $20 \%$ piperidine in dimethylformamide for $2 \times 10 \min (2 \times 10 \mathrm{~mL})$. Then the solution is drained and the resin was washed with dimethylformamide several times.

Final Fmoc Deprotection: After deprotection of Fmoc group from the very last amino acid residue, the resin was washed with DMF $(4 \times 2 \mathrm{~mL})$, DCM $(4 \times 2 \mathrm{~mL})$ then dried under vacuum. As an alternative way, final Fmoc deprotection can also be done in solution phase, after cleavage. In order to do that, completely dry crude product was dissolved in $20 \%$ piperidine in DMF solution. After the mixture was mixed for $10 \mathrm{~min}$. with sonication, it was precipitated with methyl-tertbutyl ether. The precipitate was centrifuged and the supernatant was poured off. The process was repeated 3-4 times until the supernatant becomes neutral by checking with $\mathrm{pH}$ paper.

Cleavage: $95 \%$ TFA, $2.5 \%$ decontaminated water and $2.5 \%$ TIPS solution (cleavage cocktail) was used to cleave the peptide sequence from resin. This cocktail (for $50 \mathrm{mg}$ peptidyl resin was needed $1 \mathrm{~mL}$ of cocktail solution) added to the resin and waited for 2 or 3 hours. Then the solution was collected. The peptide was triturated by addition of ice-cold diethyl ether. The solid was filtered off. The product was dissolved in distilled water and lyophilized.

Conversion of $\mathrm{Dbz}$ group into Nbz: After peptide elongation, the resin was washed with dichloromethane and $100 \mathrm{mg} p$-nitrochloroformate in $10 \mathrm{~mL}$ dichloromethane was added to the peptide reactor. The resin was bubbled with $\mathrm{N}_{2}$ for $40 \mathrm{~min}$. This process was repeated one more time. Then, it was washed with dichloromethane and treated with $10 \mathrm{~mL} 0.5 \mathrm{M}$ DIEA in DMF for 20 min and, finally, it washed with DMF and dichloromethane. The peptidyl-resin was dried under vacuum and the peptide was cleaved by using cleavage cocktail. The final deprotection of Fmoc was not performed.

Native Chemical Ligation: Ligation was performed at room temperature in the following ligation buffer: $6 \mathrm{M}$ guanidine hydrochloride $(\mathrm{Gn} . \mathrm{HCl}), 200 \mathrm{mM}$ potassium phosphate, $200 \mathrm{mM}$ 4mercaptophenylacetic acid (MPAA), $20 \mathrm{mM}$ tris(2-carboxyethyl) phosphine hydrochloride (TCEP. $\mathrm{HCl}$ ). Take $2.5 \mathrm{~mL}$ of stock solution of $6 \mathrm{M} \mathrm{Gn} . \mathrm{HCl}$ and $0.2 \mathrm{M} \mathrm{K}_{2} \mathrm{HPO}_{4}$ and filter using a 0.2 $\mu \mathrm{m}$ syringe-driven filter into a $20 \mathrm{~mL}$ scintillation vial containing $14.3 \mathrm{mg} \mathrm{TCEP} . \mathrm{HCl}(0.05 \mathrm{mmol})$ and $84.1 \mathrm{mg}$ MPAA $(0.5 \mathrm{mmol})$. Buffer was degassed under nitrogen for $15 \mathrm{~min}$ before the reaction. And the $\mathrm{pH}$ was set to 7.0 with $2 \mathrm{M} \mathrm{NaOH}$.

In a $20-\mathrm{mL}$ scintillation vial, the peptide containing $\mathrm{Dbz}$ group $\left(1.5 \times 10^{-3} \mathrm{mmol}\right)$ and linear peptide $\left(1.8 \times 10^{-3} \mathrm{mmol}\right)$ were dissolved in ligation buffer $(0.75 \mathrm{~mL})$ to achieve a final concentration of $2.0 \mathrm{mM}$ with regards to the peptide containing Dbz group. The reaction solution was mixed at room temperature and monitored by HPLC. 


\section{RESULTS AND DISCUSSION}

The amino acid sequence of chlorotoxin is as follows:

$1 \quad 10 \quad 16 \quad 20 \quad 30$

MCMPCFTTDHQMARKCDDCCGGKGRGKCYGPQCLCR

In order to synthesize CLTX by native chemical ligation, the sequence was split into two parts between Lys-15 and Cys-16. 15-mer peptide with methionine on its $\mathrm{N}$-terminal was synthesized having 3,4-diaminobenzamide (Dbz) group on its C-terminal. For this purpose, 3,4diaminobenzoic acid was selectively protected by Fmoc group by simple treatment with Fmoc$\mathrm{OSu}$ at basic $\mathrm{pH}$ values in $\mathrm{H}_{2} \mathrm{O} / \mathrm{CH}_{3} \mathrm{CN}$ mixture. This benzoic acid derivative was attached to Rink amide resin using standard peptide coupling conditions (HBTU-DIEA). After coupling and deprotection of Fmoc group by $20 \%$ piperidine in DMF, amino acids were coupled and FmocMCMPCFTTDHQMARK-Dbz was synthesized. At this stage, the peptide bond could form at the meta- or para-nitrogen atoms on Dbz group. These two structural isomers would not be a problem since both would give the same type of ligation reaction. Before cleaving the peptide from the resin, Dbz group was converted into $\mathrm{N}$-acyl-benzimidazolinone ( $\mathrm{Nbz}$ ) by the treatment with $p$-nitrophenyl chloroformate under $\mathrm{N}_{2}$ atmosphere to give two isomeric form of FmocMCMPCFTTDHQMARK-Nbz (Pep1 and Pep1').

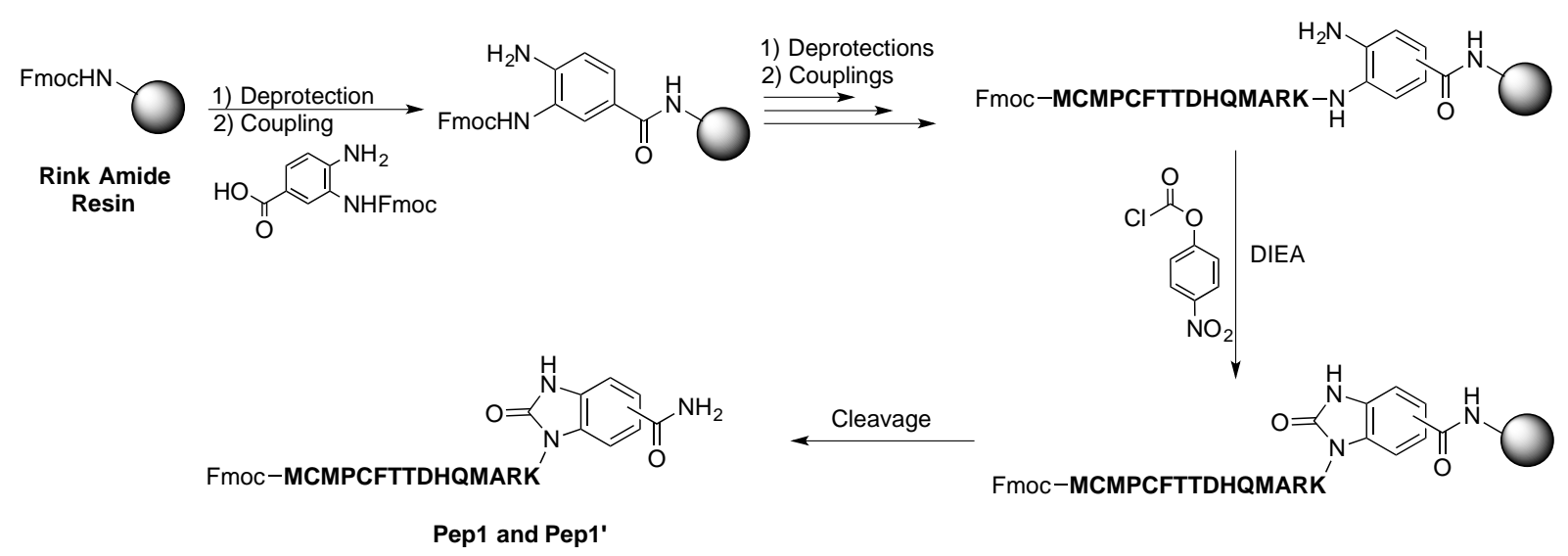

Scheme 1. Synthesis of Pep1-Pep1' starting from Rink amide resin.

Crude Pep1-Pep1' mixture was purified using reverse phase HPLC on a C18 semi-preparative column and characterized by LC-MS (Figure S1).

21-mer peptide (CDDCCGGKGRGKCYGPQCLCR)(Pep2) was synthesized in a native form using standard Fmoc-SPPS conditions on Rink amide resin. After cleaving it from resin, it was purified by reverse phase HPLC C18 semi-preparative column and characterized by LC-MS (Figure S2). 
Ligation of Pep1 and Pep2 was performed in ligation buffer which was developed by Kent and Dawson $(8,10)$. For this purpose, Pep1 and Pep2 were dissolved in ligation buffer with a final concentration of $2 \mathrm{mM}$. The reaction mixture was stirred at room temperature and monitored by HPLC.

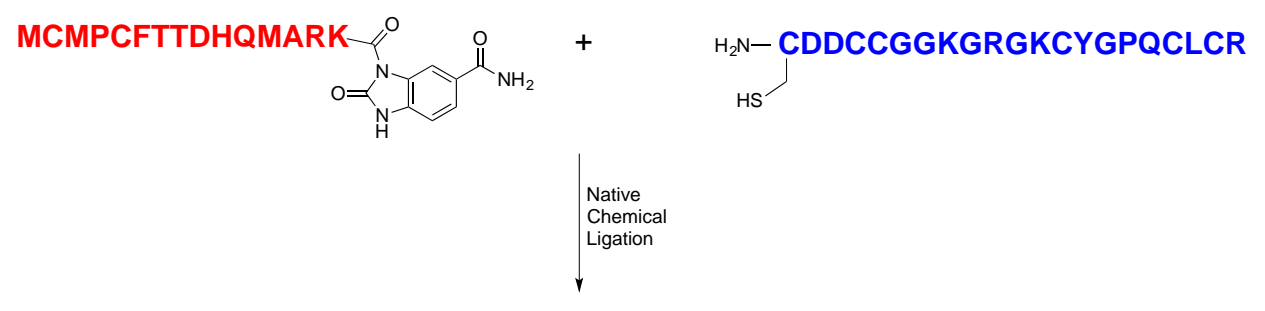

\section{MCMPCFTTDHQMARK-CDDCCGGKGRGKCYGPQCLCR}

(Chlorotoxin)

Scheme 2. Synthesis of CLTX via native chemical ligation.

Figure $2 \mathrm{~A}$ and $2 \mathrm{~B}$ show the HPLC chromatogram of pure Pep1 and Pep2, respectively. Two isomeric peaks from Pep1 and Pep1' had very separated retention times (10.5 and $23 \mathrm{~min}$.). Figure $2 \mathrm{C}$ represents the ligation mixture immediately after mixing ( $t=0$ hour). The peak appeared at 20.3 minutes is 4-mercaptophenylacetic acid (MPAA) that was used in ligation buffer. Between the time after mixing the peptides in ligation buffer and taking an aliquot, it was even possible to see the formation of ligation product (Fmoc-CLTX) as the new peak appeared at 21 minutes. In Figure 2D, it was shown that after 1 hour, the amount of ligation product started to increase and those of Pep1 and Pep2 started to decrease. 


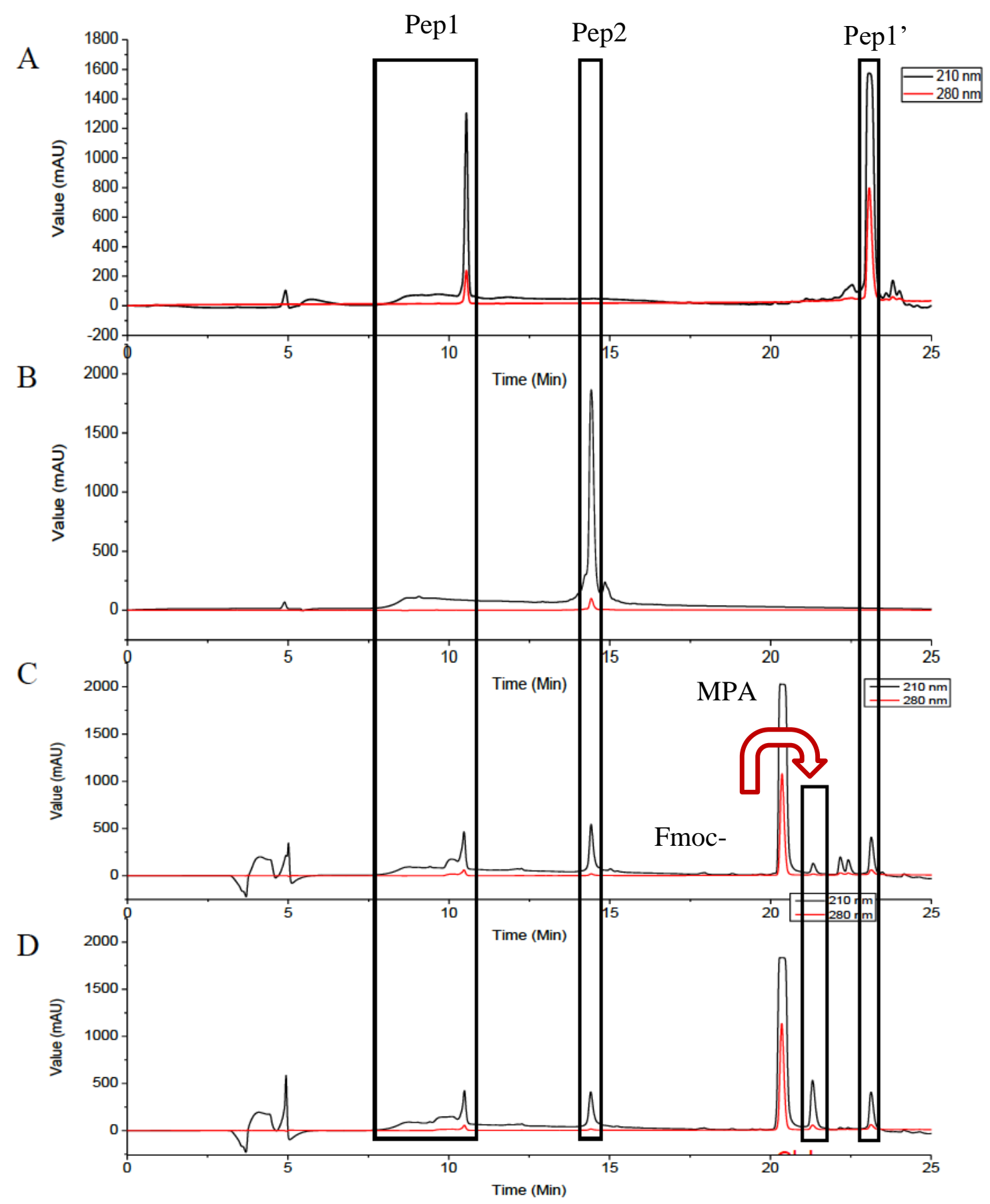

Figure 2. RP-HPLC monitoring of native chemical ligation between Pep 1 and Pep2 at 210 and 280 nm using C18 column. A. Pure Pep1-Pep1' mixture. B. Pure Pep2. C. The ligation reaction at $\mathrm{t}=0 \mathrm{~h}$. C. The ligation reaction at $\mathrm{t}=1 \mathrm{~h}$.

After ligation was over (overnight), the reaction mixture was diluted by water and purified using semi-preparative RP-HPLC C18 column and Fmoc-CLTX was obtained in pure form. It was characterized by LC-MS (Figure S3).

In conclusion, the synthesis of chlorotoxin was successfully completed by native chemical ligation. The overall efficiency of the synthesis was found to be in the range of $5-10 \%$. Ligation 
method found to be more efficient and easier in purification compared to the one-step synthesis of chlorotoxin which resulted less than $1 \%$ yield and required several purifications (7).

\section{ACKNOWLEDGMENTS}

We would like to thank METU-BAP and TUBITAK $214 Z 083$ for financial support.

\section{REFERENCES}

1. Debin, JA, Maggio JE, Strichartz, GR. Purification and characterization of chlorotoxin, a chloride channel ligand from the venom of the scorpion. Am. J. Physiol. Cell Physiol. 1993; 264(2):C361C369.

2. Deshane J, Garner CC, Sontheimer H. Chlorotoxin Inhibits Glioma Cell Invasion via Matrix Metalloproteinase-2. J. Biol. Chem. 2003; 278(6):4135-4144.

3. Veiseh M, Gabikian P, Bahrami SB, Veiseh O, Zhang M, Hackman RC, Ravanpay AC, Stroud MR, Kusuma Y, Hansen SJ, Kwok D, Munoz NM, Sze RW, Grady WM, Greenberg NM, Ellenbogen RG, Olson JM. Tumor Paint: A Chlorotoxin:Cy5.5 Bioconjugate for Intraoperative Visualization of Cancer Foci. Cancer Res. 2007; 67(14):6882-6888.

4. Yang C, Hou VW, Girard EJ, Nelson LY, Siebel EJ. Target-to-Background Enhancement in Multispectral Endoscopy with Background Autofluorescence Mitigation for Quantitative Molecular Imaging. J. Biomed. Opt. 2014; 19(7):076014.

5. Kesavan K, Ratliff J, Johnson EW, Dahlberg W, Asara JM, Misra P, Frangioni JV, Jacoby DB. Annexin A2 Is a Molecular Target for TM601, a 51 Peptide with Tumor-Targeting and AntiAngiogenic Effects. J. Biol. Chem. 2010; 285(7):4366-4374.

6. Akcan M, Stroud MR, Hansen SJ, Clark RJ, Daly NL, Craik DJ, Olson JM. Chemical Re-engineering of Chlorotoxin Improves Bioconjugation Properties for Tumor Imaging and Targeted Therapy. J. Med. Chem. 2011; 54(3):782-787.

7. Elvheim, I. S. Design, Synthesis and Structural Studies of Relaxin Receptor Modulators. 2011; Master's thesis, Universitetet i Tromsø.

8. Behrendt R, White P, Offer J. Advances in Fmoc Solid-Phase Peptide Synthesis. J. Pept. Sci. 2016; 22(1):4-27.

9. Dawson P, Muir T, Clark-Lewis I, Kent S. Synthesis of Proteins by Native Chemical Ligation. Science 1994; 266(5186):776-779.

10. Blanco-Canosa JB, Dawson PE. An Efficient Fmoc-SPPS Approach for the Generation of Thioester Peptide Precursors for Use in Native Chemical Ligation. Angew. Chem. Int. Ed. 2008; 120(36):6957-6961.

11. Amblard M, Fehrentz J, Martinez J, Subra G. Methods and Protocols of Modern Solid Phase Peptide Synthesis. Mol. Biotechnol. 2006; 33:239-254. 